\title{
Produção de textos com crianças na educação infantil
}

\author{
Texts production with children in early childhood education
}

\author{
Producción de textos con niños en la educación infantil
}

\author{
Cláudia Maria MENDEs GonTiJO* \\ MARGARETE SACHT GÖES**
}

\begin{abstract}
RESUMO
Este artigo discute como crianças de 4 anos de idade, matriculadas em uma instituição educativa infantil pública, ao serem incentivadas a escrever, produzem textos, utilizando desenhos e escrita para dialogar com os destinatários imaginários, personagens de uma história infantil. Adota, em termos metodológicos, a abordagem sócio-histórica, em que o diálogo com as crianças é a principal fonte de conhecimento. Para a análise dos dados produzidos, toma por base os pressupostos teóricos de Mikhail Bakhtin, a partir da perspectiva enunciativo-discursiva, cuja concepção de linguagem ajuda a compreender o desenho e a escrita em sua dimensão discursiva. Por defender a importância do destinatário na produção textual e por entender que esta se constitui na interlocução com o outro, analisa produções das crianças para interlocutores imaginários. Conclui que a produção de textos possibilita a enunciação das crianças por meio de diferentes linguagens.
\end{abstract}

Palavras-chave: Educação infantil. Linguagens. Crianças. Produção de textos.

\begin{abstract}
This paper discusses how four-year old children, enrolled in a public educative institution for children, when encouraged to write, produce texts using drawings and writings in order to dialogue with imaginary targets and characters of a children's story. It uses, in methodological term, the social-historic approach, in which conversation with children is the main knowledge source. For the analysis of the produced data, it is based on Mikhail Bakhtin theoretical assumptions, from the enunciative discursive perspective, which language conception assists on the understanding of the drawing and writing according to its discursive dimension. Due to defending the importance of the target in the textual production and understanding that it is constituted in the interlocution with the other, the work analyzes the children productions for imaginary interlocutors. As a conclusion, the text production enables children enunciation through different languages.
\end{abstract}

Keywords: Children education. Languages. Children. Text production.

\section{RESUMEN}

Este artículo discute como niños de 4 años de edad, inscriptos en una institución educativa infantil pública, al ser incentivadas a escribir, producen textos, utilizando dibujos y escritura para dialogar con los destinatários imaginários, personajes de una historia infantil. Adopta, como metodologia, el abordaje sociohistórico, en el cual el diálogo con los niños es la principal fuente de conocimiento. Para el análisis de los datos producidos, se toma por base los presupuestos teóricos de Mikhail Bakhtin, a partir de la perspectiva enunciativo discursiva, cuya concepción de lenguaje ayuda a comprender el dibujo y la escritura en su dimensión discursiva. Por defender la importancia del destinatário en la producción textual y por entender que esta se constituye en la interlocución con el otro, analisa producciones de los niños para interlocutores imaginarios. Concluye que la producción de textos posibillita la enunciación de los niños por medio de diferentes lenguajes.

Palabras clave: Educación infantil. Lenguajes. Niños. Producción de textos.

\footnotetext{
*Doutora em Educação pela Universidade Estadual de Campinas. Universidade Federal do Espírito Santo - UFES. E-mail: <clammg@terra.com.br>.

**Doutora em Educação pela Universidade Federal do Espírito Santo. Núcleo de Estudos e Pesquisas em Alfabetização, Leitura e Escrita do Espírito Santo - UFES.E-mail: <mgoes@hotmail.com.br>.
} 


\section{CONSIDERAÇÕES INICIAIS}

Crianças pequenas produzem textos? Nas práticas pedagógicas da educação infantil, esse tipo de produção acontece? É possível pedir que as crianças escrevam textos nessa etapa da educação básica? Acreditamos que, desde a mais tenra idade, elas podem ser levadas a expressar suas ideias por meio de textos. No entanto, a depender da concepção teórica que fundamenta o trabalho pedagógico nas instituições educativas infantis, as respostas a essas perguntas podem ser sempre negativas, principalmente quando a compreensão de língua/linguagem, de sujeito e de texto se assenta em uma visão etapista do desenvolvimento infantil. A partir dessa perspectiva, as crianças aprendem a desenhar e, depois, a escrever. Mais especificamente, é preciso aprender a distinguir a escrita do desenho para que as crianças iniciem o processo de evolução da escrita. Tal percepção está presente nos estudos de Ferreiro e Teberosky (1985), Ferreiro (1987) e em muitas outras pesquisas que partem das teorizações dessas autoras, como Goodman (1987), Tolchinsky (1987) e Carraher (1990). Conforme apontado por Ferreiro (1987, p. 104), ao discutir a relação desenho e escrita, "um dos problemas que as crianças enfrentam para constituir uma escrita é definir a fronteira que a separa do desenho" (grifos das autoras deste artigo). Nessa direção, afirma também que, "no início da diferenciação entre desenho e escrita [...], as grafias distribuem-se livremente no espaço disponível" (FERREIRO, 1987, p. 107). O aparecimento de grafias organizadas linearmente assinala o início da evolução da escrita que ocorre a partir dessa distinção.

Diferentemente dessas teorizações, buscamos, a partir da perspectiva histórico-cultural, no campo da Psicologia, entender que o desenvolvimento da linguagem é construído dinamicamente, em um ambiente históricocultural e essencialmente social. O que nos ajuda a pensar, apoiadas numa perspectiva discursiva, em uma concepção de língua, de sujeito e de texto que vê as crianças como enunciadoras, com condições de produzir textos com diferentes modos de expressão no curso do processo de aprendizagem da linguagem escrita.

A primeira perspectiva, no campo da Psicologia, parte do suposto de que o desenvolvimento da linguagem escrita tem início no momento em que as crianças começam a estabelecer as primeiras relações com o outro que vive em seu entorno. Nesse sentido, fundamentadas em Vygotsky (1929, 1996), ${ }^{1}$ aborda como diferentes linguagens mantêm relações entre si no curso do desenvolvimento infantil. Com base na perspectiva bakhtiniana de

\footnotetext{
${ }^{1}$ Para referenciar os textos dos autores da perspectiva histórico-cultural, são usadas sempre duas datas, a primeira edição em russo e a do texto atual em português: Vygotski $(1929,1996)$ e Luria $(1929,2010)$.
}

linguagem, encontram-se elementos teóricos para compreender desenho e escrita como enunciados, como o lugar da interação entre interlocutores. Dessa forma, em ambas as perspectivas, encontram-se subsídios teóricos e metodológicos para fundamentar a importância da produção de textos no intuito de que as crianças utilizem diferentes linguagens para produzir sentidos e dialogar com os outros.

Assim, este texto tem por objetivo discutir como crianças entre 4 e 5 anos de idade, matriculadas em uma instituição educativa infantil pública, ao serem incentivadas a escrever, produzem textos, utilizando desenhos e escrita para dialogar com os destinatários imaginários, personagens de uma história infantil.

Tendo em vista esse objetivo, em primeiro lugar, discutimos a apropriação da linguagem na perspectiva histórico-cultural no campo da Psicologia, o desenho e a escrita como linguagem, tomando como referência apontamentos da perspectiva de Mikhail Bakhtin, no campo da filosofia da linguagem, para fundamentar teórica e metodologicamente as situações de produção de textos que são analisadas.

\section{A APROPRIAÇÃO DA LINGUAGEM ESCRITA NA PERSPECTIVA HISTÓRICO-CULTURAL}

Vários autores têm nos ensinado muito sobre o processo de apropriação da linguagem escrita. No entanto, podemos dizer que as teorizações de Vygotsky (1929, 1996) e de Luria $(1929,2010)$, adotadas e aprofundadas por estudiosos na atualidade, Smolka (2001), Azenha (1996) e Gontijo (2008), ajudam a pensar a complexidade desse processo e suas relações com outras formas de linguagem no decorrer do desenvolvimento infantil. Vygotsky (1929, 1996) acredita, assim como nós, que a apropriação da linguagem escrita integra o desenvolvimento desta na infância e que, ao se apropriar dessa linguagem, a criança amplia e diversifica suas possibilidades de expressão e de interação com as outras pessoas.

$\mathrm{O}$ autor ressalta que a tendência, em sua época, de valorizar somente os aspectos mecânicos da escritura se refletiu na prática de ensino da linguagem escrita e na forma como era concebida teoricamente, ou seja, era vista “[...] como um hábito motor complexo, como um problema de desenvolvimento muscular das mãos [...]" (VYGOTSKY, 2000, p. 183). Por isso mesmo, no ensino da linguagem escrita, sobressaíam atividades de discriminação visual, auditiva e de coordenação motora, como requisitos necessários ao processo de aprendizagem da técnica da escrita. Apesar dessas práticas e das teorias que as fundamentam, Vygotsky (2000) já considerava, na década de 1930, que o jogo, o desenho e a escritura integram um processo mais amplo de desenvolvimento 
da linguagem, buscando compreender os elos genéticos entre esses processos.

A partir da compreensão desses elos ou relações, esse autor considera que a apropriação da linguagem escrita "[...] não segue uma linha única", uma linha evolutiva linear, como sugerem alguns estudos sobre esse processo. Com base em seus pressupostos, podemos considerar a apropriação da linguagem escrita como um processo que integra o desenvolvimento de outras linguagens, o que lhe confere um caráter complexo e não linear. Nessa direção, para Vygotsky $(1929,1996)$, a história da linguagem escrita começa "[...] quando aparecem os primeiros signos visuais na criança $[\ldots]$. O gesto se constitui como um dos primeiros mediadores entre a criança e o mundo social, ele é, precisamente, o primeiro signo visual que contém a futura escritura da criança" (p. 240). Por intermédio dos gestos, os bebês conseguem estabelecer relações de comunicação com as pessoas do seu entorno. O gesto se torna uma forma visual de linguagem em um momento em que a criança não pode comunicar-se verbalmente. Em determinadas situações, pode ser pensado, segundo o autor, como uma escrita no ar, pois não é uma linguagem para ser ouvida e sim para ser vista/lida.

Da mesma maneira que aponta nexos genéticos entre o gesto e a escrita, Vygotsky $(1929,1996)$ afirma que existem esses nexos entre os gestos, as brincadeiras, os desenhos e a escrita no processo de desenvolvimento da linguagem na infância. Nesse sentido, é importante sublinhar, por exemplo, que, para o autor (1929, 1996, p. 188):

[...] el juego simbólico infantil puede entenderse como un sistema del lenguaje muy complejo que mediante gestos informa y señala el significado de los diversos juguetes. Sólo en la base de los gestos indicativos, el juguete va adquiriendo su significado; al igual que el dibujo, apoyado al comienzo por el gesto, se convierte en signo independiente.

Dessa forma, no jogo simbólico infantil, os gestos indicam os significados dos brinquedos na brincadeira, ou seja, objetos são usados quando a criança pode realizar com eles os gestos usados pelos adultos em situações da vida. As crianças escolhem, para brincar de mamãe filhinha, por exemplo, somente objetos que permitem realizar gestos de ninar, de amamentar, de trocar fraldas, pois significam o cuidado de uma mãe com o seu bebê. Estes dão sentido aos objetos que escolheram ou que têm disponíveis para brincar. Portanto, no jogo, um objeto pode se converter em uma boneca, porque permite fazer com ele gestos de cuidados com o bebê, porque são estes que conferem ao objeto, na brincadeira, os sentidos.

Assim como na brincadeira, inicialmente, também os desenhos infantis se apoiam nos gestos, demonstrando laços genéticos entre ambos. Primeiro, segundo Vygotsky (1929, 1996), as crianças desenham de memória, ou seja, elas desenham o que sabem, o que conhecem sobre o mundo social e físico. Por isso, esses desenhos são incompreensíveis para os adultos e são explicados por elas com o auxílio de gestos. Como dito, elas desenham o que conhecem e não o que veem. Isso implica dizer que, mesmo que seus registros não sejam facilmente compreendidos pelos adultos, as crianças desenham, elegendo traços distintivos dos objetos ou que permitem identificá-los. Por isso, essa atividade exige delas abstração e não reprodução do que veem.

Para Vygotsky (1929, 1996), o desenho constitui a atividade artística preferencial das crianças, e sua origem, como atividade gráfica, pode ser encontrada nos rabiscos, a mesma origem da escrita. Em determinadas situações, ao desenhar, a criança relata a construção de suas produções como se narrasse uma história. Linguagem oral e grafismos se misturam no processo de construção de sentidos. Um mesmo rabisco pode significar diferentes objetos ou pessoas, dependendo do modo como às crianças narram seus desenhos. Para esse autor, nessa situação, a linguagem oral é produzida em momento posterior à produção do desenho, portanto, não existe um planejamento, uma intenção para tal.

Quanto ao estudo sistemático e profundo da linguagem escrita, Vygotsky $(1929,1996)$ afirma que foi Luria $(1929$, 2010) que se dedicou a ele. Esse último autor interessouse por entender processos de desenvolvimento da escrita em sujeitos que não frequentavam a escola. A partir desses estudos, concluiu que esse processo começava antes de os sujeitos por ele pesquisados entrarem na escola. É importante acentuar, no estudo de Luria, os elos entre o gesto, o desenho, a brincadeira e a escrita. Nesse sentido, o autor verificou que as primeiras produções gráficas desses sujeitos, que ainda não permitiam lembrar o conteúdo que as motivou, tinham caráter imitativo. Isto é, os sujeitos da pesquisa do autor, que não compreendiam a função mnemônica da linguagem escrita, imitavam os gestos dos adultos ao escrever. Mesmo aqueles que começaram a compreender essa função, em certos momentos, transformavam a escrita em uma brincadeira, ou seja, produziam escritos sem se importarem com as palavras e frases que pretendiam registrar. A compreensão da função mnemônica da escrita decorreu da descoberta de que, para lembrar as palavras ou frases que escreviam, podiam usar desenhos, pois, mesmo que estes não traduzissem exatamente o conteúdo que desejaram registrar, continham elementos que permitiam evocá-los.

Assim, os estudos de Vygotsky e Luria demonstram os elos genéticos entre gesto, brincadeira, desenho e escrita, indicando possibilidades para pensar o desenho e a linguagem escrita, no curso do processo de aprendizagem 
da linguagem escrita em instituições educativas, como processos relacionados entre si e que permitem, desde muito cedo, a produção de sentidos pelas crianças por meio de atividades gráficas. As separações dessas linguagens, transformadas em matérias escolares, é uma produção da escola, decorrente das práticas e teorizações que asseguram que a evolução da escrita somente terá início quando as crianças distinguirem escrita e desenho. Essa distinção se faz necessária quando a escrita é vista apenas como um sistema de símbolos que representam os sons da fala. Nas práticas adotadas em muitas escolas, um caminho que permite levar as crianças a ter essa compreensão é ensinar, por exemplo, que a escrita serve para escrever nomes dos objetos do mundo social e físico, algo que o desenho não pode representar, pois este retrata diretamente esses objetos. A Figura 1 apresenta exercícios com essa finalidade, e a Figura 2 traz exercícios que

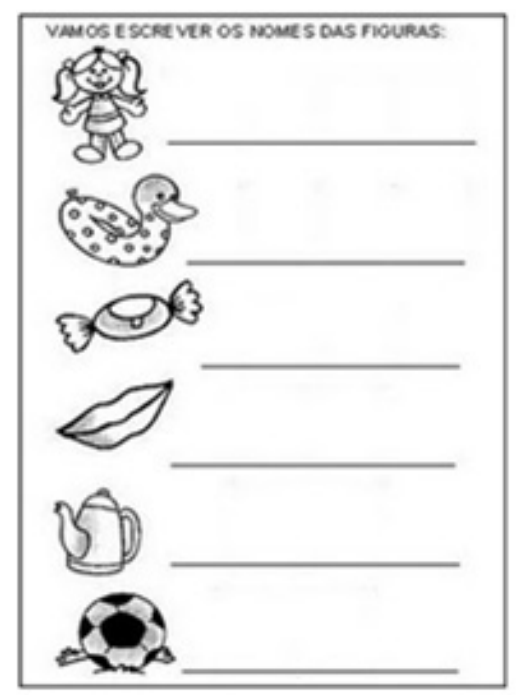

Figura 1.

Escrita de nomes

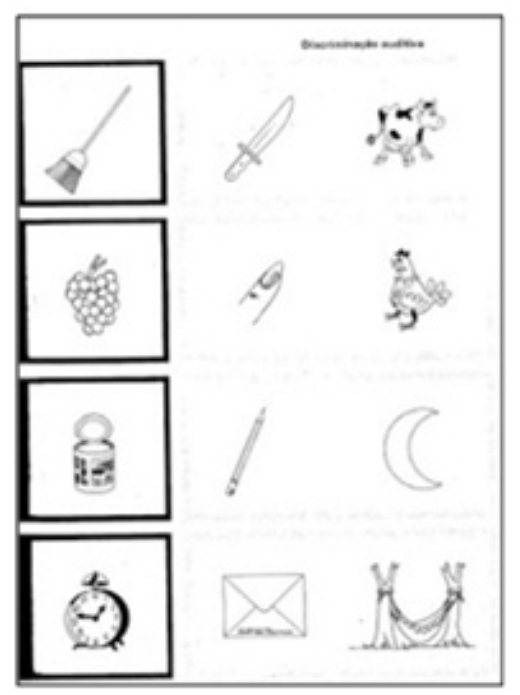

Figura 2.

Discriminação auditiva levam as crianças a discriminar unidades da fala e seu correspondente gráfico, no caso específico, as letras que representam sílabas.

Na Figura 1, os objetos já estão representados pelos desenhos. Agora é necessário escrever seus nomes, algo que não pode ser desenhado, apenas escrito com letras. A própria ideia do trabalho com os nomes próprios está fundada nessa relação. E a criança pode desenhar seu colega, mas o nome do colega somente pode ser escrito.

Na pesquisa de Góes (2014), cuja finalidade foi compreender as relações entre desenho e escrita, uma das estratégias que a professora encontrou para levar as crianças a distinguir desenho e escrita foi à definição de materiais diferentes para escrever e desenhar: lápis preto para escrever e lápis de cor para desenhar. Entendemos que esse tipo de estratégia, além de restringir as possibilidades de uso de materiais pelas crianças, limita as possibilidades de expressão. Se observarmos a página de um livro de literatura (Figura 3), verificamos que os textos são compostos com diferentes linguagens.

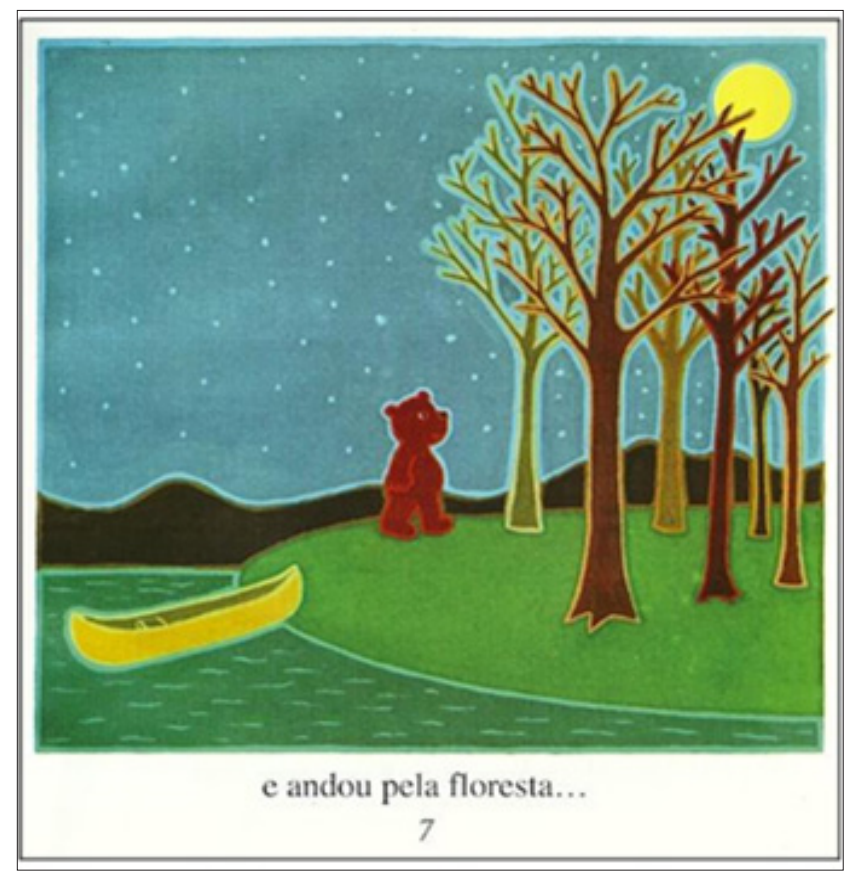

Figura 3. Página do livro Feliz aniversário lua (Fonte: ASCH, Frank. Feliz aniversário lua. São Paulo: Global, 1982)

Na página do livro, o texto é composto por várias linguagens: imagens (desenhos), número e escrita. Isso acontece com a maioria dos textos que lemos nos jornais, nas revistas, nos livros de histórias etc. No dia a dia, os diferentes portadores textuais são apresentados assim, entretanto a escola se incumbe de fazer a cisão entre essas linguagens, pois compreende que, para as crianças aprenderem a ler e escrever, precisam distinguir essas 
linguagens. A proposição aqui é pensar na possibilidade de as crianças aprenderem a ler e a escrever na e com a diversidade de linguagens que compõem os textos. Para isso, no entanto, é necessário que a produção de textos tenha lugar central no processo de ensino-aprendizagem da linguagem escrita e se compreenda o desenho e a escrita como linguagem, ou seja, como lugar de interação. Esboça esse último aspecto no próximo tópico, ao construir as bases teóricas e metodológicas deste artigo.

\section{DESENHO E ESCRITA COMO LINGUAGEM}

Fundamentando-se em Bakhtin (2010), compreendemos a linguagem como um dizer que está sempre relacionado com um acontecimento, com um sentido nas interações verbais, isto é, a enunciação, entendida como "[...] produto da interação de dois indivíduos socialmente organizados e, mesmo que não haja um interlocutor real, este pode ser substituído pelo representante médio do grupo social ao qual pertence o locutor" (BAKHTIN; VOLOCHINOV, 2010, p. 116). Assim, para esses autores, um enunciado não se constitui no sujeito como ato criativo individual, ele se compõe na interação verbal com o outro.

Dessa maneira, os sujeitos só reagem a um enunciado quando eles despertam um sentido relativo à sua própria vida, pois, como mencionam Bakhtin e Volochinov (2010, p. 101), “[...] toda enunciação, mesmo na forma imobilizada da escrita, é uma resposta a alguma coisa e é construída como tal. Não passa de um elo da cadeia dos atos de fala". Bakhtin (2000) também ressalta que o enunciado é um elo na cadeia da comunicação verbal, uma "[...] unidade da comunicação discursiva" (p. 295). Sendo assim, podemos pensar que o desenho e a escrita são produções discursivas e não criações individuais, pois se constituem na inter-relação com os pares dos sujeitos que os produzem. Conforme assinala Bakhtin (2000), o autor de uma obra, texto, desenho ou escrita, assim como o locutor, também responde a enunciados anteriores e posteriores.

Desse modo, em termos metodológicos, a partir de uma abordagem de pesquisa de cunho sócio-histórica, é importante perceber, nos textos produzidos pelas crianças e durante a sua composição, o diálogo com a pesquisadora responsável pela produção dos dados, com os interlocutores do seu texto, com o mundo social, ou seja, com as inúmeras vozes com as quais dialogam e suas evidências nas produções das crianças. Quando estas se posicionam em relação ao enunciado dos outros, elas se tornam ouvintes, potencializadas a dar respostas: “[...] O locutor termina seu enunciado para passar a palavra ao outro ou para dar lugar à compreensão responsiva ativa do outro" (BAKHTIN, 2000, p. 294), proporcionando a alternância dos lugares dos interlocutores - ora falantes, ora respondentes.

Sendo assim, os enunciados estão endereçados a um ou mais interlocutores. $\mathrm{O}$ endereçamento constitui-se em um traço essencial na cadeia discursiva. A fim de se entender a questão do endereçamento proposta por Bakhtin (2000), tomamos o trecho em que esse autor diz que "[...] o papel dos outros, para os quais o enunciado se elabora [...] é muito importante" (p. 320). Qualquer gesto ou palavra estão sempre carregados de sentido, o que provoca no outro uma atitude responsiva. Na concepção de sujeito bakhtiniana, o ser não é passivo, isto é, receptor; pelo contrário, ao se ouvir e compreender um enunciado, adota-se uma atitude responsiva, transformando e atuando no ato enunciativo, com gestos, fala, desenhos e escrita. Dessa forma, a resposta ao que foi produzido é que engendra a continuidade ou o fim temporário, mínimo da enunciação nesse processo de comunicação discursiva.

Assim, nos eventos vivenciados pela pesquisadora com crianças entre 4 e 5 anos de idade, em uma instituição educativa infantil pública, foi construído um contexto em que a produção de textos, de enunciados, possibilitasse a elas conversar e expor suas ideias para resolver situaçõesproblema. Desmistificando, assim, a concepção de que criança pequena não sabe produzir textos, sabe apenas desenhar e que, para aprender a escrever, precisa, primeiramente, distinguir desenho e escrita. Para todas as propostas de produção, buscamos levar em conta os ensinamentos de Geraldi (1997). Segundo o autor, as crianças, ao produzirem os textos, precisam ter o que dizer/escrever, sentirem-se motivadas para tal e terem para quem dizer/produzir textos. Verifica-se que, desse modo, as crianças podem se constituir em locutores responsáveis por seus dizeres e também escolher as estratégias para elaborar suas produções, sem se preocupar em distinguir linguagens.

É necessário ressaltar que o texto é compreendido, neste artigo, como um elo na comunicação discursiva. Desse modo, é definido aqui da mesma forma que Bakhtin (2003) elabora conceitualmente a noção de enunciado, como elo de uma corrente discursiva que responde a outros textos e instaura outros discursos.

\section{ProduÇões INFANTIS PARA INTERLOCUTORES IMAGINÁRIOS}

Diante do que foi exposto nos tópicos anteriores, acreditamos que as crianças muito pequenas possam produzir textos para os outros, desde que não sejam limitadas as formas de linguagem que utilizam em suas produções. Para exemplificar essas possibilidades, tomaremos exemplos do trabalho realizado por Goes (2014) com crianças entre 4 e 5 anos de idade numa 
instituição pública de educação infantil. Abordaremos uma das propostas de produção de textos realizadas por essa pesquisadora com as crianças cujo endereçamento eram interlocutores imaginários, isto é, os personagens da história $O$ megaplano do lobo, de autoria de Melanie Williamson, publicada pela Editora Panda Books.

Essa história foi lida pela pesquisadora para as crianças em partes, em momentos distintos: no primeiro momento, foi lida a parte em que o lobo diz que estava com a dentadura quebrada e, por isso, precisava comprar uma nova. No segundo momento, o trecho em que as intenções do lobo são reveladas, ou seja, ele desejava consertar a dentadura para comer as ovelhas, personagens da história. Finalmente, no terceiro momento, foi lida a parte em que as ovelhas construíram um plano para defender os filhotes das investidas do lobo. Em todos os três momentos, as crianças foram incentivadas a produzir textos, participando da história e dialogando com as personagens: primeiro, para o lobo, segundo, para as ovelhas e, terceiro, para os filhotes das ovelhas.

No primeiro momento, ao terminar a leitura da primeira parte da história, as crianças foram provocadas pela pesquisadora a escrever um plano para ajudar o lobo a comprar uma dentadura. Foi enfatizada a necessidade do lobo e como a ajuda deles era importante nesse momento. Todas as crianças demonstraram querer ajudar o lobo, mas de maneiras diferentes: umas queriam ajudar a comprar a dentadura, porque acreditavam que o lobo era bom e entenderam que ele estava com dor de dente; outras queriam ajudar o lobo a comer as ovelhas, pois acreditavam que o problema dele era fome e, na perspectiva delas, não se pode deixar ninguém com fome.

Gabriela (4 anos e 10 meses), ${ }^{2}$ uma das crianças participantes da pesquisa, ao expor graficamente o plano para socorrer o lobo (Figura 4), seguiu procedimentos aprendidos na sala de atividades com a professora. Ela iniciou seus registros escrevendo o próprio nome. Para tal, utilizou o lápis grafite, mantendo, assim, as orientações que constantemente recebia: para escrever nomes, é usado esse tipo de lápis. Também escreveu algumas letras, pois já dominava um número considerável, incluindo letras do próprio nome, para, somente depois, desenhar a casa do lobo e o próprio lobo também com lápis grafite. Gabriela separou suas escritas com um contorno, começando a leitura de baixo para cima. Disse, quando questionada, que escreveu o próprio nome, depois o lobo pedindo pra ir na festa e, ao lado direito, ele vai na festa e ganha uma dentadura de zumbi.

\footnotetext{
2 Utilizaram-se, para denominar as crianças, nomes fictícios (personagens de histórias e filmes).
}

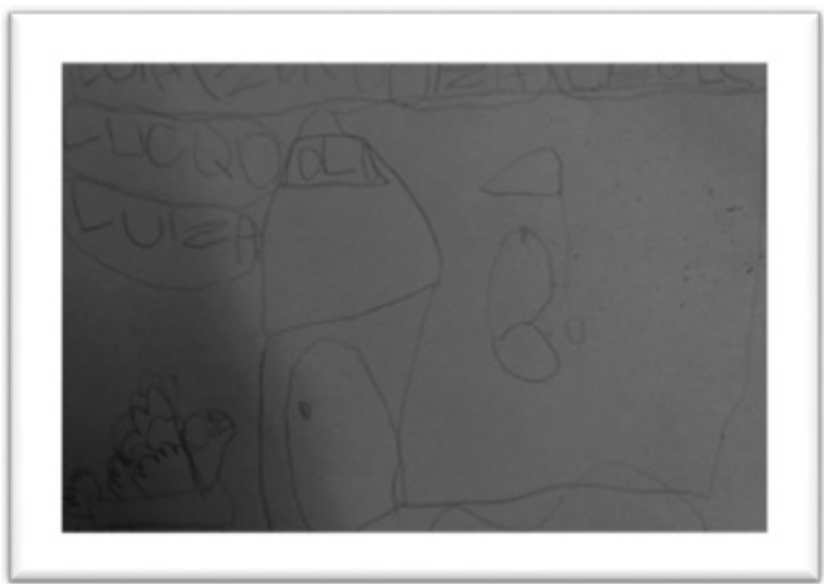

Figura 4. Plano da Gabriela para ajudar o lobo (Fonte: Acervo pessoal)

$\mathrm{P}^{3}$ : "E você, Gabriela, qual é o seu plano para ajudar o lobo?".

Gabriela: "Aqui, o lobo pedindo pra ir na festa (referindo-se às letras próximas do lobo) (...) sabe aquela dentadura de zumbi que você ganha... não tem? Ele vai na festa e ganha uma dentadura de zumbi".

P. "Hum... que ideia bacana, Gabriela... boa ideia! E aqui? Você escreveu o quê?" (referindo-se às letras na parte superior da folha).

Gabriela: "Eu escrevi 'festa'... porque é à festa que ele vai".

Gabriela produziu o texto com desenhos e escrita. Essas duas linguagens estão entrelaçadas com a finalidade de dar sentidos, de produzir o texto que relatou verbalmente para a pesquisadora. Nessas condições, a criança compreendeu que poderia criar textos dessa maneira. Em primeiro lugar, ela explicou oralmente a produção, isto é, mostrou, com gestos, onde escreveu sobre o lobo pedindo para ir à festa. Explicou a que tipo de festa ele iria, aquela onde as crianças ganham dentadura de zumbi. Esse era o plano para ajudar: o lobo precisava ir a uma festa em que ganhasse uma dentadura de zumbi. Nas relações com a pesquisadora, com o lobo, a criança produziu o texto, criando um ótimo plano para ajudar o lobo. Porém, acreditamos que a produção de sentidos os diálogos - foi possível, porque a criança pôde utilizar desenho e escrita como linguagens para expressar suas ideias graficamente.

No segundo momento da leitura, reveladas as verdadeiras intenções do lobo - conseguir uma dentadura

\footnotetext{
3 Utilizou-se a letra P para identificar a pesquisadora responsável pela produção dos dados com as crianças. Além disso, é necessário ressalvar que, para as transcrições desses eventos, tomou-se por base as normas apresentadas por Fávero, Andrade e Aquino (2003). As crianças escolheram, sozinhas, o nome que queriam. A pesquisadora apenas propôs que cada uma escolhesse um nome diferente para ser personagem do livro que ela estava escrevendo.
} 
para comer as ovelhas -, os textos orais produzidos na roda de conversa com os colegas sempre manifestaram o sentido de cuidar e proteger as ovelhas do lobo. Assim, dessa vez, as crianças foram incentivadas a produzir um plano para ajudá-las a escapar do lobo. É interessante notar que, no início das pesquisas, ou seja, no começo do período escolar, a maioria das crianças elaborava suas produções somente com desenhos, porém isso foi se alterando no decorrer do ano. Nesse momento inicial, mesmo Super-Homem ( 5 anos e 2 meses), que perguntava sempre se era para desenhar ou escrever, utilizava, como se mostraremos a seguir, apenas desenhos (Figura 5) em suas produções. Abaixo, o fragmento que mostra o momento em que Super-Homem chama a pesquisadora até a sua mesa para ver o que ele havia feito.

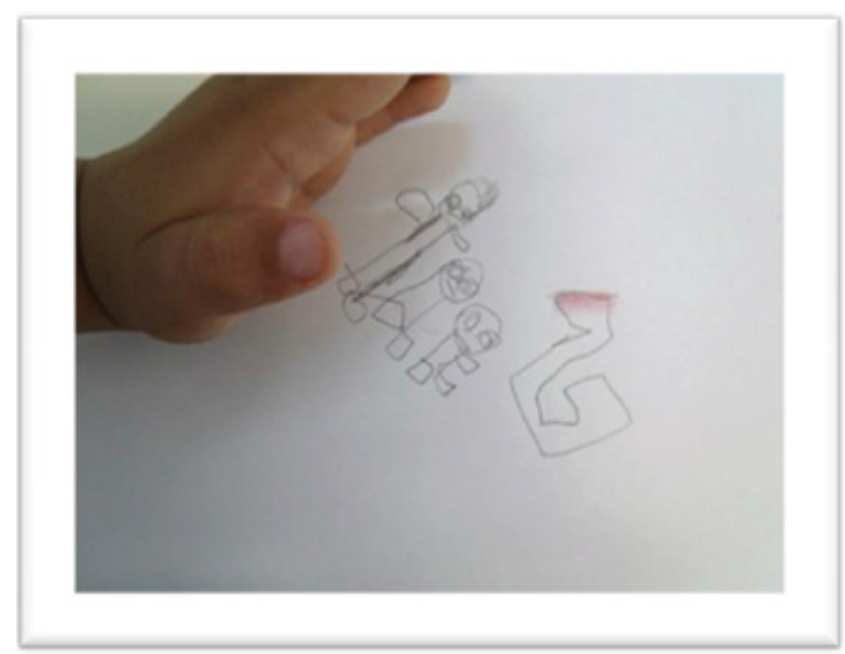

Figura 5. Plano do Super-Homem para ajudar as ovelhas (Fonte: Acervo pessoal)

Super-Homem: “Tia... ó: o lobo. (apontando para a figura maior). Esta é ovelha... ovelha... e o CA- RACOL".

P: "E o que vai acontecer aí? O que você escreveu para a ovelha?".

Super-Homem: O lobo... ovelhas... (apontando para os desenhos)... você vai TÊ a ideia de tirar os dentes... e... as ovelhas vão tirar os dentes do Lobo... essa é a ideia...".

Inicialmente, Super-Homem se propôs a desenhar as personagens da história, mas o fato de querer explicar o que produziu o levou a arquitetar o plano relatado verbalmente. Em seguida, dialogou com as personagens para as quais a sua produção estava dirigida: "Ovelhas, você vai tê a ideia de tirar os dentes". Desse modo, disse para elas o plano. Depois, à pesquisadora: "As ovelhas vão tirar os dentes do lobo, essa é a ideia”. Nessas condições, pode-se pensar que o desenho das personagens o ajuda a construir o plano, por isso, primeiro dialoga com as ovelhas, dizendo-lhes a ideia para não serem devoradas pelo lobo e, depois, informa o plano ou a ideia à pesquisadora que o questionou.

Gabriela também escreveu para as ovelhas, mas, diferentemente do que ocorreu com Vampiro Cowboy, ao produzir o texto, usou escrita e desenho (Figura 6).

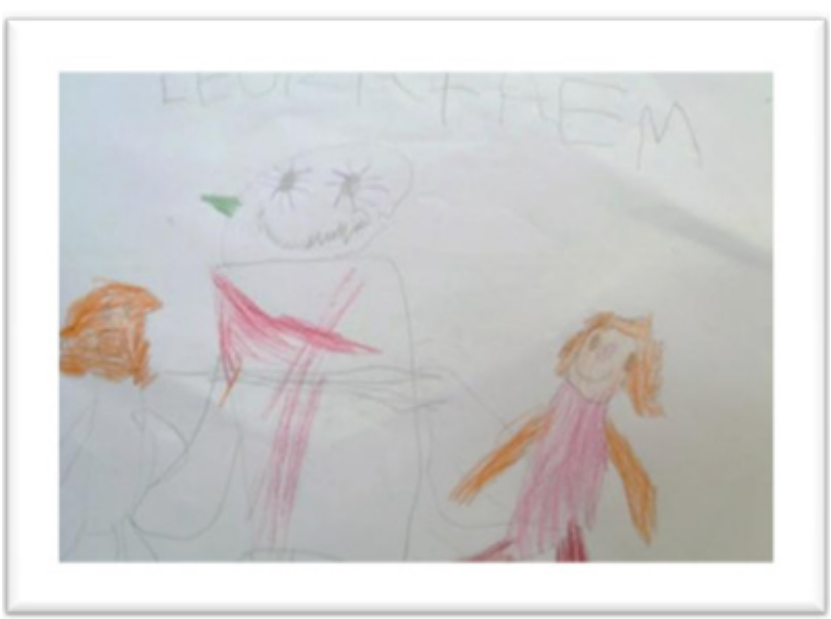

Figura 6. Plano de Gabriela para ajudar as ovelhas (Fonte: Acervo pessoal.)

Gabriela: "As duas ovelhas amaRRA... amarrou o lobo... aqui a corda..." (mexendo com o lápis e apontando primeiro para as duas ovelhas e depois para uma linha que cortava por inteiro o corpo do lobo).

P: “Ah, é? Ela amarrou? E por que ela amarrou? O que ela quer fazer com o lobo?".

Gabriela: "É que ele ia coME ela... ela amarrou a boca dele..." (apontando agora para a boca).

P: "Hum... entendi..." (silêncio).

Gabriela: "Puxou assim, ó... (gesticulando com as mãos) e amarrou assim... ficou assim ó... pra frente..." (aperta com as duas mãozinhas os lábios, formando um biquinho, como se o lobo estivesse com a boca costurada).

Gabriela narrou a sua produção, primeiro, dizendo que as duas ovelhas amarraram o lobo. Mostrou a corda usada por elas. Informou ainda que amarraram a boca do lobo, porque ele queria comê-las. Os desenhos apresentavam detalhes de formas e de conteúdo, o que permite compreender o que queria enunciar. Ao narrar sua produção, lançou mão dos gestos, do corpo e do tom de voz para contar o plano elaborado: "Amarrou assim... ficou assim ó... pra frente...”. Seu corpo inteiro participou da narrativa. Como mencionado, Vygotsky $(1929,2007)$ acredita que os gestos mantêm relações com a brincadeira, com os desenhos e com a escrita. 
No caso específico, ajudou a completá-lo, demonstrando alguns detalhes não presentes no texto. Dessa forma, podemos constatar que os gestos, a dramatização da cena, dão sentido aos desenhos, à escrita e também aos enunciados orais. A menina (Gabriela) também brincou com as palavras, percebendo semelhanças sonoras entre as sílabas que compõem as palavras lobo e bolo. Divertiu-se com a brincadeira, com a falta de sentido ou com o sentido criado: amarra o bolo.

A partir das situações de produção apresentadas, podem-se sublinhar alguns aspectos importantes. Primeiro, a complexa inter(ação) entre as crianças, as personagens, a pesquisadora, a produção gráfica que constituíram os sentidos, isto é, os planos. O segundo aspecto, talvez o mais importante, diz respeito à participação da criança por inteiro no processo de produção de sentidos: corpo, brincadeiras, gestos, enunciados orais e gráficos entram em uma complexa relação, que busca elaborar ou dar sentido, no caso específico, ao plano para ajudar as ovelhas.

Para o desenvolvimento da última proposta, que era escrever para os filhotes das ovelhas, a pesquisadora conversou muito com as crianças sobre todos os planos elaborados até aquele momento. $\mathrm{Na}$ última parte da história, no final do livro, aparecem placas com mensagens. Ao ser questionado se sabia o que estava escrito nas placas, Príncipe, um dos sujeitos, rapidamente, disse: "Nomes!". Dessa maneira, respondeu de acordo com o ensinado pela professora da turma: a escrita é utilizada para escrever nomes.

A pesquisadora disse, então, que não eram nomes e sim algumas orientações para as ovelhas se prevenirem das investidas do lobo. Ao serem questionadas novamente, foram surgindo, então, várias ideias como: "Não confiar no lobo", "não ficar longe da mamãe dela", "não fugir de casa", "ficar de blusa de frio", "fechar a porta da casinha", "colocar uma roupa quentinha...". Nessas falas, podemos verificar que imaginação e realidade se misturam, pois, ao mesmo tempo em que falavam das ovelhas, enunciavam vivências e experiências com suas mães. Solicitamos, então, às crianças que escrevessem outros combinados para os filhotes das ovelhas, para que eles não corressem o risco de serem comidos pelo lobo. A seguir, o combinado produzido por Príncipe (4 anos e 3 meses), que desenhou (Figura 7) somente a ovelha, sem se preocupar em colocar o próprio nome ou inserir letras.

Príncipe: "NÃO fuja da mãe..." (como se conversasse com a ovelha).

P: "Isso mesmo: NÃO fuja da mãe..." (tentamos entrar na conversa dele com a ovelha).

Príncipe: "Eu não fugi quando eu saí pa pasSEA com a minha mãe..." (direcionando sua fala para a pesquisadora).
P: "Você não fugiu?". (balança a cabeça que não).

Príncipe: "Então, ovelhinha, oh: NÃO FUJA DA MÃE... fica pertinho porque senão... (voltando-se novamente para conversar com a ovelhinha que desenhou).

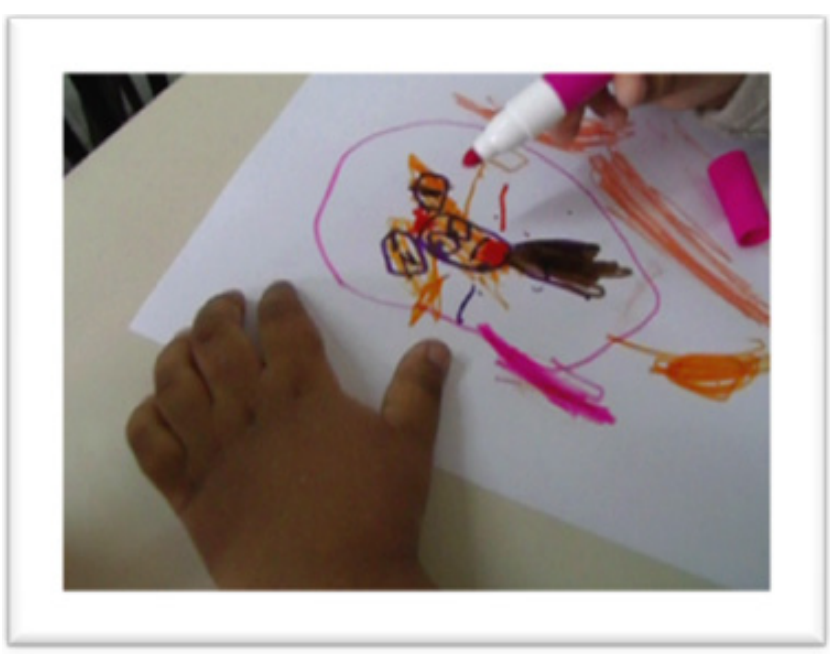

Figura 7. Plano de Príncipe para ajudar as ovelhas (Fonte: Acervo pessoal)

Ao produzir o texto, primeiro, aconselhou a ovelha a não ficar longe da mãe. Certamente, trouxe para esse texto uma experiência vivida. Crianças não devem se afastar da mãe, "senão" algo terrível pode acontecer. Nesse movimento, as palavras de Príncipe e de sua mãe se misturam e dão sentido à produção, isso porque, como sublinham Bakhtin e Volochinov (2009, p. 154), “[...] tudo que é dito está situado fora da alma do falante e não pertence somente a ele". Nessa perspectiva, o discurso de um sujeito singular é sempre habitado por outras vozes e, assim, haverá um discurso narrado e enunciado (discursivizado), no qual estará sempre presente a voz de um interlocutor e a voz do outro. Para Bakhtin (2010), o discurso elaborado por um sujeito particular vem do outro, por isso não é totalmente seu. $\mathrm{O}$ discurso de um comparece no discurso do outro, dando-lhe sentido.

No diálogo com os filhotes e com a pesquisadora, Príncipe participou com sua experiência de vida, pois, ao mesmo tempo em que aconselhou os filhotes a não fugirem da mãe, informou à pesquisadora que não fugiu da sua mãe, quando saiu para passear. Para confirmar seu conselho, retomou o diálogo com os filhotes e aconselhou, mais uma vez, a não fugirem da mãe, a ficarem pertinho dela, mas, dessa vez, advertiu que, se fugissem, algo poderia acontecer. Com relação ao diálogo com as crianças, é relevante assinalar a importância de ouvi-las, conversar com elas para compreender suas intenções. Leite (2006, p. 64-65) ressalta que: 
[...] Toda experiência vivida deixa, sim, marcadas a carne, o imaginário, a subjetividade de cada um. Assim, para conhecer as crianças, devo estar com elas - ouvi-las, vê-las, conversar com elas, trocar, brincar, partilhar experiências, procurar perceber onde se posicionam e, assim, capturar o que pensam e sentem, o que querem revelar, desvelar, esconder, transformar, poetizar.

Certamente, essas marcas aparecem e podemos perceber isso na produção discursiva de Príncipe, pois ele revela o vivido. Ao mesmo tempo, como parte das descrições narrativas gráficas sobre o que quer representar (VYGOTSKY, 2009), existe uma liberdade para trazer elementos que são cabíveis somente na própria imaginação da criança. Apesar de compreender os dois mundos (da imaginação e da realidade), a criança transita pelos dois e realiza a produção.

\section{CONSIDERAÇÕES FINAIS}

Discutimos como crianças matriculadas em uma instituição educativa infantil pública, ao serem incentivadas a escrever, produzem textos, utilizando desenhos e escrita para dialogar com destinatários imaginários, personagens de uma história infantil. Nas situações analisadas, constatou-se que as crianças produziram textos. Em termos práticos, foi essencial, no processo de produção, a presença de interlocutores e também o fato de terem o que dizer para as personagens por se sentirem motivados para tal.

Como observado, as situações ou atividades propostas asseguraram que as crianças elaborassem os planos para auxiliar as personagens a partir de várias linguagens: gráfica (desenho e escrita), gestual e oral. Desse modo, em termos teóricos, as situações analisadas permitem revelar que desenho, escrita e gestos se relacionam nos processos de produção de sentidos. É interessante verificar que, apesar de a pesquisadora perguntar sobre o que escreveram e pedir que criassem textos, as crianças produziram os enunciados para o lobo e para as ovelhas relacionando desenho e escrita. Isso não significa que não sabiam diferenciar essas duas linguagens. Elas sabiam, porque a professora ensinava tais diferenças e também porque perguntavam o que deveriam fazer: desenhar ou escrever. O que levou a criança a tomar as duas formas de linguagem é o fato de se sentirem motivadas a dizer algo para alguém, a participar da história, sugerindo planos para a ovelha e para o lobo. Talvez, se as crianças tivessem sido incentivadas a escrever palavras ou nomes das personagens, o resultado da produção teria sido outro.

De modo geral, as análises reforçam a ideia de que a produção de textos é essencial, pois é por meio dessa atividade que a criança percebe que pode produzir formas diferenciadas de linguagem. Como assinala Bakhtin (2010, p. 209),

[...] a linguagem só vive na comunicação dialógica daqueles que a usam. É precisamente essa comunicação dialógica que constitui o verdadeiro campo da vida da linguagem. Toda a vida da linguagem seja ela qual for o seu campo de emprego [...] está impregnada de relações dialógicas.

As relações, na perspectiva bakhtiniana, ocorrem entre sujeitos que se integram e se constituem no mundo da cultura e na vida. Os sujeitos são produtores de textos que respondem a enunciados e, nesse sentido, podem ser mais bem compreendidos nessas situações. As crianças, na sala de atividades da educação infantil, constituem-se em interlocutores que têm muito a nos dizer sobre os processos que se formam nesse espaço. Assim, o diálogo com as crianças na pesquisa permitiu compreender o que pensam, como agem para responder às demandas escolares e de escrita. Para Bakhtin (2003, p. 348), a vida é "[...] dialógica por natureza" e, portanto, “[...] viver significa participar do diálogo: interrogar, ouvir, responder, concordar etc. Nesse diálogo, o homem participa inteiro e com toda a vida: com os olhos, os lábios, as mãos, a alma, o espírito, todo o corpo, os atos".

Nas relações dialógicas com as crianças, a linguagem aparece como o lugar do construto, do sentido e da interação. Esse sentido que constitui o eu e o outro como sujeitos histórico-culturais acontece somente na conversa, nas relações. Assim, constata-se que o trabalho de produção de textos liberta as crianças de exaustivas atividades de cópias de letras, nomes e frases presentes na educação infantil. Isso porque a concepção de texto está vinculada à aquisição de um código linguístico que se fundamenta somente na transcrição do oral para o escrito e vice-versa. Propicia ainda a libertação em relação a fases previamente determinadas que levam à cisão das linguagens com as quais a criança pode dialogar.

Assim, para finalizar, podemos dizer que, como estudado por Vygotsky e Luria, diferentes linguagens participam dos processos de constituição de sentidos dos textos e ajudam a constituí-los. Para as crianças da pesquisa, o importante era participar da história, auxiliar as personagens e, para isso, não produziram cisões entre as linguagens que conheciam, ou seja, o desenho e a escrita. Esse ensinamento advindo dos diálogos com as crianças leva a afirmar que, para aprender a produzir textos, as crianças precisariam ser inseridas em espaços pedagógicos que lhes permitissem agir mais livremente, a usar, sem necessidade de distinção, várias linguagens que circulam nos livros, nas mídias, na sociedade. Para isso, também seria necessário que a produção de textos 
ganhasse centralidade nas práticas das diferentes etapas de escolarização, principalmente na educação infantil e nos primeiros anos do ensino fundamental.

\section{REFERÊNCIAS}

BAKHTIN, Mikhail. Problemas da poética de Dostoiévski. Rio de Janeiro: Forense Universitária, 2010.

Fontes, 2000.

Estética da criação verbal. São Paulo: Martins Fontes, 2003 .

Estética da criação verbal. São Paulo: Martins

BAKHTIN, Mikhail; VOLOCHINOV. Marxismo e filosofia da linguagem. São Paulo: Hucitec, 2010.

CARRAHER, Terezinha N. Construtivismo e alfabetização: um balanço crítico. Educação em Revista, Belo Horizonte, v. 12, dez. 1990.

FERreiro, Emília; TEBEROSKY, Ana. Psicogênese da língua escrita. Porto Alegre: Artes Médicas, 1985.

FERREIRO, Emilia. Os processos construtivos da elaboração da escrita. In: FERREIRO, Emília; PALACIO, Margarita Gomez. Os processos de leitura e escrita: novas perspectivas. Porto Alegre: Artes Médicas, p. 102-123, 1987.

GERALDI, João Wanderley. Portos de passagem. 4. ed. São Paulo: Martins Fontes, 1997.

GOODMAN, Yetta. O desenvolvimento da escrita em crianças muito pequenas. In: FERREIRO, Emília; PALACIO, Margarita G. Os processos de leitura e escrita: novas perspectivas. Porto Alegre: Artes Médicas, 1987. p. 85-101.

GÓES, Margarete Sachte. As relações entre desenho e escrita no processo de apropriação da linguagem escrita.
Tese (Doutorado - não publicada) - Universidade Federal do Espírito Santo, Vitória, 2014.

GONTIJO, Cláudia Maria Mendes. A escrita infantil. São Paulo: Cortez, 2008.

LEITE, Maria Isabel. A criança desenha ou o desenho criança? A ressignificação da expressão plástica de crianças e a discussão crítica do papel da escrita em seus desenhos. In: OSTETTO, Luciana Esmeralda; LEITE, Maria Isabel (Org.). Arte, infância e formação de professores: autoria e transgressão. São Paulo: Papirus, 2006. p. 64-65.

LURIA, Alexander Romanovich. O desenvolvimento da escrita na criança. In: VIGOTSKI, Lev Semenovich; LURIA, Alexander Romanovich; LEONTIEV, Alekséi Nikoláyevich. Linguagem, desenvolvimento e aprendizagem. 4. ed. São Paulo: Ícone, 1989. p. 143-189.

SMOLKA, Ana Luiza Bustamante. A criança na fase inicial da escrita: a alfabetização como processo discursivo. 10. ed. São Paulo: Cortez; Campinas, SP: Editora da Universidade Estadual de Campinas, 2001.

TOLCHINSKY, Liliana; LEVIN, Iris. O desenvolvimento da escrita em crianças israelenses pré-escolares. In: FERREIRO, Emília; PALACIO, Margarita G. Os processos de leitura e escrita: novas perspectivas. Porto Alegre: Artes Médicas, 1987. p.143-158.

VYGOTSKY, Lev Simenovich. A imaginação e a arte na infância. Lisboa: Relógio d'Água, 2001.

Obras escogidas. Madrid: Visor, 1996. Tomo III.

A construção do pensamento e da linguagem. Tradução de Paulo Bezerra. São Paulo: Martins Fontes, 2000.

Recebido em 05-09-2015.

Aprovado em 31-03-2017 